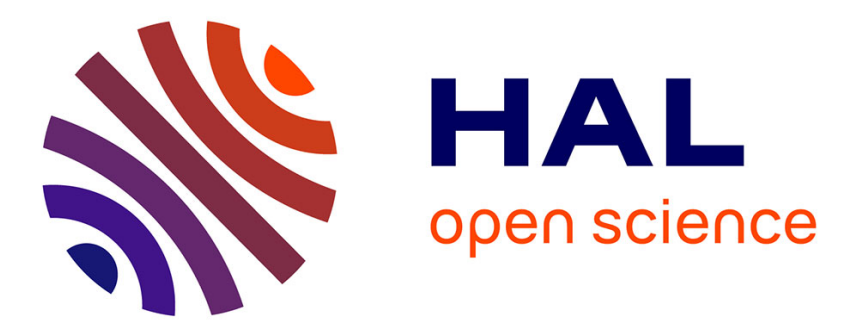

\title{
Genre awareness and rhetorical appropriacy: manipulation of information structure by NS and NNS scientists in the international conference setting
}

Elizabeth Rowley-Jolivet, Shirley Carter-Thomas

\section{- To cite this version:}

Elizabeth Rowley-Jolivet, Shirley Carter-Thomas. Genre awareness and rhetorical appropriacy: manipulation of information structure by NS and NNS scientists in the international conference setting. English for Specific Purposes, 2005, 24 (1), pp.41-64. 10.1016/j.esp.2003.09.003 . hal-00275961v2

HAL Id: hal-00275961

https://shs.hal.science/hal-00275961v2

Submitted on 27 Jun 2008

HAL is a multi-disciplinary open access archive for the deposit and dissemination of scientific research documents, whether they are published or not. The documents may come from teaching and research institutions in France or abroad, or from public or private research centers.
L'archive ouverte pluridisciplinaire HAL, est destinée au dépôt et à la diffusion de documents scientifiques de niveau recherche, publiés ou non, émanant des établissements d'enseignement et de recherche français ou étrangers, des laboratoires publics ou privés. 
English for Specific purposes (Elsevier), Vol 24 (1), 41-64.

\title{
http://www.sciencedirect.com/science
}

\section{Genre awareness and rhetorical appropriacy: manipulation of information structure by NS and NNS scientists in the international conference setting.}

\begin{abstract}
Acquiring proficiency in different discourse genres involves an awareness of which syntactic structures are the most appropriate to the communicative context and purpose. This article examines two scientific research genres - conference proceedings articles and conference presentations - and compares the syntactic behaviour of a group of native speaker (NS) scientists with that of non-native speaker (NNS) scientists. The aim of the study is to investigate whether NNS scientists are able to adapt their syntax to the specific discourse requirements of each genre. The comparison is made from the point of view of information structure. In English, certain specialised syntactic structures, such as passives, clefts, inversion, and extraposition, afford a certain latitude on the discursive level, enabling the enunciator to orient the informational weight of clauses according to the effect required. The findings clearly indicate that while NS scientists manipulate information structure in a context- and genre-sensitive way, NNS scientists show much less grammatical adaptability to the information packaging requirements of the discourse genre, particularly in their oral presentations. It is argued that this has a negative impact on the rhetorical appropriacy and persuasiveness of their discourse.
\end{abstract}

Key Words: Scientific genres; extraposition; inversion; passive; pseudo-clefts; information structure; pragmatic competence; NS / NNS discourse

\section{Introduction}

Research scientists nowadays, whatever their native origin, often have to communicate in English to gain acceptance and international recognition for their work. The majority of them however are not native English speakers, and communicating their research in English can be a considerable challenge, as in addition to linguistic and cultural obstacles, they need to master a wide range of spoken and written genres of academic 
communication - research articles, grant proposals, poster and conference presentations, lectures and seminars, etc. As Sengupta, Forey \& Hamp-Lyons point out, even "English native speaker-like competency does not guarantee that the individual has the skills to manipulate the production of academic genres ... which are essential components for success in academia" (1999: 8).

A crucial element in genre awareness is the ability to produce a discourse that is appropriate to the situation or context (Bazerman, 1994). This entails taking into account the targeted audience (Nwogu \& Bloor 1991), the communicative purpose of the discourse, and the conventions socially constructed by the discourse community, which in turn will impact on the linguistic choices made (Swales, 1990 and forthcoming). One of the thorniest problems that scientific researchers need to address is how to package the information they wish to communicate. In expository discourse such as scientific research communication, the information content is high; syntactic management of this information load is therefore a primary consideration. The purpose of scientific research communication is however not only informative, but also rhetorical, in that it aims to persuade. To achieve this dual purpose, mastery of the information flow requires a syntactic organisation that is adapted to the genre, communicative context, and audience.

Probably the most fundamental factor impacting on information packaging is the difference between writing and speech (Chafe 1986; Chafe \& Danielewicz 1987; Dubois 1980 and 1987; Halliday 1989). Interest in spoken academic genres is however fairly recent (Thompson 1997; Simpson \& Swales 2001; Ventola, Shalom \& Thompson 2002). Our own work on physics research discourse (Carter-Thomas \& Rowley-Jolivet 2001 and forthcoming) has shown that native speaker (NS) scientists express themselves very differently in spoken and written research genres, namely their conference presentations and their research articles (RA). The information packaging arrangements and subsequent choice of syntactic structures adopted were found to be motivated to a great extent by the particularities of each discourse context. In this study, we will compare the syntactic behaviour of a group of NS scientists with a group of non-native speaker (NNS) scientists to see whether the latter also adapt their syntax to discourse requirements in the same way. Are the information packaging strategies adopted by NNS in the RA and the conference presentation appropriate for these two research genres?

The aim of this comparison is not to give a normative account of the language proficiency of the two groups: the NNS scientists in our data are proficient in English, and express themselves correctly both when writing and when speaking. The question we asked ourselves was, rather, the following: are NNS scientists aware of the association between genre, syntactic structures and rhetorical persuasiveness? Such a comparison can, we believe, be usefully linked to the linguistic notion of information structure. 


\section{Information Structure}

Information structure, generally regarded as encompassing the notions of Theme/Rheme and Given/New, examines the way the information conveyed by the discourse is packaged into informational units within and between clauses, so as to provide clear instructions about the relative saliency of units and to guide the (potential) receiver towards an appropriate understanding in the precise discursive context.

Although the view of information structure adopted in the present article is broadly based upon that of systemic functional linguistics (Halliday 1994; Thompson 1996) we will also be drawing upon theories of a more cognitive persuasion (Chafe 1987; Lambrecht 1994) so as to address more closely questions related to cognitive input and shared knowledge in the two genres examined

Clauses in spoken as well as written discourse have a structure appropriate for the presentation of information. Generally speaking the theme, as the point of departure of the message, will contain Given (or recoverable) elements that the listener can readily identify, making it easier for the receiver to link the clause to the preceding text and/or discursive context, and paving the way at the same time for what is then developed in the rheme. New elements of information concerning this theme will figure afterwards in the rheme. It is important to note here though that Given and New do not necessarily apply to the literal degrees of giveness or newness of particular referents but to information that is presented as recoverable or on the contrary as nonrecoverable and thus 'newsworthy' (Halliday 1994: 298; Fries 1994: 231).

Given information, being often conflated with the clausal theme will usually precede New or newsworthy elements of information and as a rule the clause will gradually gain in communicative dynamism (Firbas 1992), often culminating in spoken English with the focal nuclear stress placed on an item in clause final position. The rise in information load also frequently corresponds to the actual size and complexity of clause items, with long complex elements tending to occur towards the end of the clause, thus easing the processing burden of the receiver, a phenomenon frequently referred to as 'end-weight'.

This type of organisation with Given information first and New information second, reinforced by the principle of end-weight and final focal stress, is considered to be the unmarked option for organising the information, and is often rendered in English by an SVO structure, where the grammatical subject of an active verb provides the thematic anchorage, with the verb complex and object constituting the New or rhematic part of 
the clause ${ }^{1}$. However this SVO order is not always sufficient or suitable to create a coherent text. In order to respect unmarked information structure enunciators may be obliged to use a different syntactic arrangement. They may also choose to reverse the usual information packaging arrangements, deliberately placing New before Given, in order to give certain elements of information particular salience or focus. For these reasons, they need to have at their disposal a battery of linguistic resources so as to indicate unambiguously, either through prosody or syntax, the most appropriate information packaging arrangement.

We have chosen to concentrate on the syntactic resources available for indicating information status and focus $^{2}$. Even in a language of fairly fixed word order such as English there are a number of specialised syntactic structures such as the passive, cleft constructions, extraposition, inversion and existential there, which enable the enunciator to manipulate different clause constituents and thus explicitly denote a particular information packaging arrangement. Whilst these structures are theoretically available at all times, their deployment depends to a large degree on the choice of a particular enunciator, within a particular mode (oral or written) and communicative context.

Selecting a particular information packaging arrangement therefore requires a certain pragmatic competence. The enunciator needs to take into account aspects such as: the very different cognitive processing constraints between written and spoken discourse, and the different resources available in each mode for indicating salience and focus; features of the communicative context which impact on the recoverability / accessibility of referents (such as the presence of the visual channel of communication; see Rowley-Jolivet 2002); and, more broadly, the co-enunciative relationships considered standard practice within the particular genre. All of these pragmatically motivated features, as we shall see in the detailed discussion of each specialised structure, play a decisive role in creating a discourse that is contextually appropriate and rhetorically effective.

\section{Research Design}

A corpus of oral conference presentations and proceedings articles was collected, comprising a double set of parallel texts: 9 oral presentations given by NS scientists at an international physics conference and the 9 corresponding articles from the conference book of proceedings, plus a similar set of 9 conference presentations and proceedings articles by NNS, also in physics ${ }^{3}$. The presentations were recorded on video and then transcribed. In each sub-set, the parameters held constant between the oral and written papers are: the scientific

\footnotetext{
1 See (Carter-Thomas 2000, Chap. 2) for a more detailed account of information structure and the interaction between syntax and information structure.

${ }^{2}$ The role of prosody in Information Structure will not be dealt with in the present article
} 
research topic (identical for each presentation-article pair); the author (the speaker is in all cases one of the authors of the written paper); the audience (other researchers in the same speciality), and the occasion (the physics conference). The only variable parameter, therefore, is the mode, oral or written. To control for possible bias due to field-specific characteristics or to the relatively small size of the corpus (18 presentations and 18 articles), the quantitative results for the presentations were checked against a larger reference corpus comprising 90 conference presentations, half by NS and half by NNS researchers, in three scientific fields, geology, medicine, and physics, totalling 170,000 words, and statistical tests (Student-Fisher) were run on this larger corpus $^{4}$.

We will first present the quantitative findings on the frequency of occurrence of the specialised syntactic structures in each sub-set.

\section{Quantitative Findings}

As can be seen from Table 1, clauses overall, as one would expect, are appreciably longer in the written than in the spoken mode (13.2 words per clause in NS articles $v s .9 .5 \mathrm{w}$. in their oral presentations, $15.9 \mathrm{w} . v s$. $12.4 \mathrm{w}$. in NNS articles $v s$. presentations), due to a lower verbal density in the articles: the verbal densities, expressed as the number of verbs per 1000 words are, respectively, $75 \%$ (articles) and 103\% (presentations) for NS, and 63\% (articles) and 81\% (presentations) for NNS. Note, however, that clauses in NNS texts, both articles and presentations, are considerably longer than in NS texts, a point we will return to below in the sections on the passive and on extraposition.

Table 2 gives the occurrences of each specialised structure in the data and clearly shows the interaction of two factors, namely mode and speaker origin, on frequency of occurrence. The use of the passive illustrates this point ${ }^{5}$. In the articles of both groups of speakers, the percentage of passives is high, around $32 \%$, confirming other studies of the RA (Barber 1962; Huddleston 1971; Banks 1993). In the presentations, in contrast, there is a significant difference between the two groups. NS differentiate strongly between the two modes, using the passive in only $8.3 \%$ of clauses in their presentations, whereas NNS, though manifesting some modal influence, with a lower percentage in their presentations than in the articles, nevertheless use the passive twice as frequently as NS when speaking, and thus differentiate much less radically between the two modes. When the

\footnotetext{
3 See Appendix I for details of the conferences and titles of the articles and presentations in the corpus. Note that only the speaker's monologue is included in the oral corpus; the discussion phase of the conference presentations is not taken into account here.

${ }^{4}$ See Rowley-Jolivet (1998, Chap. 4) for further details on the composition and selection criteria of the reference corpus.

5 See Rowley-Jolivet (2001) for a study of the passive in our reference corpus. Following Banks (1993), all verb forms containing the elements BE + -ED were taken to be passive.
} 
Final draft

search is extended to the reference corpus, a similar trend emerges. The passive is consistently more frequent in NNS presentations, with the difference being statistically significant in geology and physics $(p=.05)$.

Extraposition shows a similar modal distribution to the passive in that it is more frequently used overall in the articles than in the presentations. In the NS data, the difference in frequency between the two modes is, as with the passive, very marked ( 8 occurrences in the presentations against 51 in the articles). NNS scientists, on the contrary, make less use of extraposition than NS in their articles, but considerably more in their presentations, resulting again in a rather weak differentiation between the two modes. This finding is confirmed by the reference corpus, where extraposition is over twice as frequent in NNS presentations, a statistically significant difference $(p=.01)$.

Inversion has the opposite modal distribution to passives and extraposition, with practically no occurrences in any of the articles, but a significant number in the presentations. Yet again, the difference between modes is more marked for NS scientists, who use this structure more frequently than NNS when speaking (almost twice as frequently overall in the reference corpus, though the difference here is not statistically significant, at $p=.18$ ). Pseudo-clefts show the strongest mode- and speaker-dependent distribution: while no occurrences were found in the articles of either group (confirming Banks 1995), pseudo-clefts are relatively frequent in NS presentations (28 occurrences), but extremely scarce in NNS talks (1 occurrence). This is fully confirmed by the reference corpus, with 5 times as many occurrences in NS presentations as in NNS ones, a highly significant difference $(p=.00001)$.

These findings can be usefully compared to frequencies in two of the registers - written academic prose $(\mathrm{ACAD})$ and spontaneous conversation (CONV) - used in the corpus-based Longman Grammar of Spoken and Written English (Biber et al. 1999). This comparison reveals that, whatever the structure considered, NS presenters regularly make use of structures typical of speech (such as pseudo-clefts and inversion), and rely much less on structures considered typical of the RA (such as passives and extraposition), whereas NNS continue to rely, even when speaking, on the structures characteristic of written academic prose and make little or no use of structures more suitable for oral delivery.

Two additional structures indicated in Table 2 - It-clefts and existential there constructions - are also possible selections for the manipulation of information structure. $I t$-clefts are rarely used in our corpus, with only 2 occurrences in the articles and 3 in the presentations, and will not be examined here. Existential there structures are more abundant, particularly in the presentations, and are used in similar proportions by both 
Final draft

groups. We have analysed the main functions of this structure elsewhere (Carter-Thomas \& Rowley-Jolivet 2001; see also Huckin \& Pesante 1988).

We will now look at each of the first 4 specialised structures detailed above in turn, examining their role in information structure management and proposing explanations for the observed differences between the two groups of speakers.

\section{The Passive}

Traditionally, the passive has been considered as one of the principal means of achieving impersonality in a text, as it enables the removal of any explicit agency. It has therefore often been presented as a structure particularly suitable for scientific writing. An equally important function of the passive however lies in its information structure role. Using a passive structure enables the writer/speaker to manipulate clausal constituents and to place a specific item(s) in theme position, especially when there is a choice of candidates for topichood. The enunciator can thematise and present as Given what would normally have been a syntactic object, and hence part of the rheme, in an active clause, thus respecting the usual unmarked information packaging arrangements. In this way, the writer can maintain thematic continuity between clauses, as an inanimate element already mentioned in a previous clause can be thematised thanks to a passive in a subsequent clause. In example (1), the inanimate noun group the blocks occurring in the rheme of the first clause, is thematised in the following two passive clauses:

(1) In general it is advantageous to stress the blocks to the maximum electric field that can be tolerated....

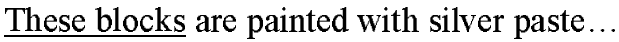

The blocks are then placed end to end $(\mathrm{A} 3)^{6}$

The thematic progression between these clauses would have been seriously disrupted if the writer had not placed the inanimate noun group in theme position, as in the manipulated example (lb):

(1b) We painted these blocks with silver paste

In example (1) the themes are brief. In many cases, however, the inanimate noun groups constituting the theme of the passive clause in the articles are extremely complex:

(2) The low current heated hollow cathode technology has been initially developed by Proel... (A11)

\footnotetext{
${ }^{6}$ Examples taken from the proceedings articles are referred to by the letter A followed by the number of the article, and examples from the oral presentations by the letter P (see Appendix I).
} 
(3) A resonantly-charged five-stage 70-Ohm Blumlein pulse-forming line is triggered by a thyratron. (A7)

The scientific writer needs to convey as precisely and as unambiguously as possible a high density of information. The heavily pre-modified noun groups of many passive clauses enable the writer to condense this quantity of information into the clausal theme.

The high proportion of passive structures used by both the NS and NNS scientists in their writing matches the findings of other studies of scientific journal articles, indicating that NNS in our corpus conform to NS expectations in their use of the passive in writing. In the presentations, however, considerable differences between the two groups emerge. NS scientists differentiate particularly strongly in their use of the passive in the written and oral modes, using four times fewer passives in the presentations than in the articles $(8.3 \%$ vs. $32 \%)$. This has several repercussions on information structure management. Both the clauses themselves and the clausal themes in the NS presentations are, for example, much shorter and less explicit than in the articles, facilitating information processing for the listener. The information conveyed by the highly explicit and precise thematic nominal group and passive combination of the written text is frequently omitted in the presentation either because it is present on the visuals projected or because the shared enunciative context naturally disambiguates the discourse and makes further explanation unnecessary. The small number of passives that are used in the NS presentations occur principally in the methods section, a section which is in any case much shorter in the presentation, due to time constraints.

Instead of the passive, NS presenters use a high proportion of personal pronoun animate syntactic subjects as themes followed by an active verb (see Table 3). Example (4) is a typical case:

$\underline{\text { NS Article }}$

(4 Output pulses with durations in the range of 80-600 We've been able to extend the waveforms up to 600

) nsec are demonstrated. It is shown that these nanoseconds in pulse width and we've demonstrated Blumlein pulsers can be developed into light and with relatively little effort an ability to significantly compact devices without degradation in their reduce the size and weight of the pulsers (P2) performances. (A2)

Almost half $(46.8 \%)$ of the clausal themes in the NS presentations consist of a personal pronoun, in most cases one with an animate subject:

(5) We conducted tests of both Mylar and Kapton. You get about forty times the life with Kapton. (P2)

(6) I tried to measure a mass difference, I figured that I'm exploding something off the surface... and I could 
Final draft

not measure anything to within 0.1 grams... (P7)

The speaker's choice to orient these clauses around personal themes makes the presentation far livelier. The contrast with the corresponding section of the article is here stark.

The use of the first and second person singular pronouns $I$ and you by the NS presenters would appear particularly significant, creating very different interpersonal relations to those of the article. In terms of classical rhetoric, the writer's 'ethos' in the articles is that of phronèsis: sober deliberation, objectivity, a careful weighing up of the pros and cons, expressed in collective terms by we and not as a purely personal opinion ( $I$ is therefore shunned; see also Hyland 2001). In their presentations, in contrast, native speakers adopt a different ethos or 'voice' to that projected in the RA, one that is closer to arétè, i.e. a frank and direct manner, more theatrical in tone, or even eunoia, the attributes of a likeable person, who has a relation of connivance with the audience ${ }^{7}$. The use of the personal pronouns $I$ and you in preference to the passive in the presentations plays an important role in establishing this rhetorical personality (Dubois, 1980; 1981).

Personal pronouns, however, are not the only means employed by NS to establish this ethos in their presentations. Their preference for a more interactive style of presentation also comes across in their use of other non-passive strategies, as in example (7):

\section{$\underline{\text { NS Article }}$ \\ NS Presentation}

(7) ...the LCO and dipole are situated at the focus of a parabolic here's the dielectric, there's the very cylinder sub-reflector, and the $\mathrm{LCO} /$ dipole package is positioned at fat very short dipole and then a the focus of a larger $(3.7 \mathrm{~m}$ diameter) parabolic dish. ... The parabolic sub-reflector behind that... modulator, L-C oscillator, dipole, and sub-reflector are enclosed in Put it all in a plastic box (P1) a plastic box. (A1)

The 3 passives used for the spatial description in the article are replaced by inversions using the deictics here and there in the presentation. This use of inversion, as we shall see below, is particularly useful in the conference setting where the speaker has to integrate both visual and verbal information. Instead of the distanciation automatically provided by the passive (Chafe 1982), a feeling of inclusion and immediacy is created, as the audience's attention is focused on the new information presented on the slide.

Non-native presenters, in contrast, use twice as many passive constructions as NS do $(17 \% v s .8 \%$ of clausal choices). As a result, they differentiate less in their choice of voice between the oral and written modes, and indeed seem to have some difficulties deciding exactly what sort of 'voice' to adopt for the oral discourse 
Final draft

genre. Several of the NNS presentations show a marked lexico-grammatical parallelism between the spoken and written versions:

\section{NNS Article}

NNS Presentation

(8) The mass reduction benefits associated to the Electric propulsion can be a key issue when applied adoption of ion propulsion can be, in particular, to small satellites... In particular, the small satellites retained a key factor also when referred to small, in the range between three hundred and eight resource limited satellites (called also lightsats) ... hundred kilograms have been proposed, alone or in The massive utilisation of lightsats (generally in the constellations to perform a variety of missions... the range $300-800 \mathrm{~kg}$ ), alone or in constellations, has drag compensation of LEO spacecraft that are been diffusely proposed during the last years for a generally devoted to earth observation... (P11) number of applications. (A11)

There are 3 passive constructions in the presentation reproduced here (two finite passives and one reduced passive). The first two passive constructions in particular are very closely modelled on the written text. The theme choices, being almost exclusively inanimate objects, further reinforce the distance between the speaker and the discourse situation.

Elsewhere in the NNS corpus there are several examples of passive constructions preceded by very complex, and therefore heavy, clausal themes:

(9) ..the first and most important maybe attempt in the creation of the inductive storage generator coupled to the X-ray source was carried out in Tomsk on the new installation GIT4. (P16)

This part of the talk would probably be difficult for the audience to process, as such highly explicit and precise thematic nominal groups, typical of the written text, are extremely difficult to interpret 'in real time' during a presentation.

Reflecting the same tendency, the use of personal pronouns in the NNS presentations is also less frequent (see table 3). Particularly revealing are the figures for the use of you in thematic position, which represents only a minor proportion of themes overall compared to the NS presentations. This combination, in NNS presentations, of a fairly heavy use of the passive, very infrequent use of you, and, when a pronoun is used as theme, of we in preference to $I$, creates a similar ethos to that of the RA. Unlike their NS peers NNS do not

\footnotetext{
7 Barthes (1985: 146). See also Gill \& Whedbee (1997).
} 
Final draft

seem intent on installing a feeling of connivance or empathy with their listeners, and seem to feel uncomfortable with establishing their authority on personal grounds ${ }^{8}$.

\section{Extraposition}

Extraposition is a frequent structure in the RA, where it regularly occurs as semi-formulaic 'lexical bundles' such as 'it should be noted that...', 'it can be seen that...' (Biber et al., 1999). The explanation for this high frequency in the RA can, we believe, be found in the information packaging role of this structure.

In extraposition, the semantically empty or anticipatory it in initial position in the matrix clause refers to a clausal item, either non-finite or finite, placed in the postponed extraposed clause.

(10) It is possible to define a catch-up time in terms of the amount by which the peak of the voltage pulse catches up with the more slowly propagating base of the pulse. (A3)

(11) It should be noted that especially with low characteristic impedances the L/R time constant associated with the load can be significantly long in comparison with the pulse risetime

As can be seen in example (10), the extraposed clause contains a very heavy information load. If this were placed in theme position, using the canonical structure as in the manipulated example (10b), the theme would be overloaded.

(10b) Defining a catch-up time in terms of the amount by which the peak of the voltage pulse catches up with the more slowly propagating base of the pulse is possible.

As Banks points out (1995: 7), such a complex theme as this would also more than likely contain some new elements of information. Thanks to extraposition, not only are heavy or complex grammatical units placed towards the end of the sentence, thus easing processing for the receiver and respecting the principle of endweight, but any new elements of information will automatically occur in the rheme, ensuring an increase in communicative dynamism along the left to right axis of the clause. As pointed out in the previous section, many noun groups in scientific research articles carry a high density of information, and this means that a structure such as extraposition - which enables information load to be redistributed over the sentence in a more balanced way - is particularly suitable for this discourse genre.

\footnotetext{
${ }^{8}$ Vassileva (2002) in her cross-cultural analysis of linguistics conference presentations, likewise finds $I$, we and you to be used only half as frequently by the Bulgarian speakers as the British and American speakers.
} 
Final draft

Another explanation for the frequency of extraposition in the RA concerns the phenomenon of hedging. In the above examples, as in many cases in the data, the matrix clause includes an evaluative element, an evaluation of likelihood in example (10) and of relevance in example (11). The scientist can thus make a subtle commentary on the validity of the information placed in the extraposed clause without appearing overtly in the text. Moreover, by placing this comment in clause-initial position, the position where readers expect Given (not New) information to occur, the evaluation becomes particularly difficult to challenge and is therefore rhetorically more effective (Hoey, 2000; Hewings \& Hewings 2002).

Example (11) also illustrates the link between this structure and the passive. Nearly half of the cases of extraposition in the NS articles use a passive. The combination of these two structures reinforces this impression of objectivity.

When we compare how NS and NNS use extraposition in their articles, we see that while NS use it heavily (51 occurrences, $3.6 \%$ of clausal choices), NNS use it less frequently (31 occurrences, $2.4 \%$ of clausal choices), indicating perhaps that NNS scientists are not using extraposition to its full advantage and may not be fully aware in fact of its informational and evaluative potential. One encounters, for example, passages in the NNS articles where extraposition would have been the best option but was not used:

(12) Direct power measurement of single microwave pulses involving levels of hundreds of megawatts is difficult. (A14)

Here, the theme is overloaded, leading to a very unbalanced distribution of information, whereas with an extraposed structure a much smoother information flow is achieved:

(12b) It is difficult to perform direct power measurement of single microwave pulses involving levels of hundreds of megawatts

Example (13) is another case where the NNS writer did not use extraposition, in this case for thematising his comment: So the accuracy of the method was quite bad and without significance. (A18)

The author here, instead of using heavily evaluative lexis ( $\mathrm{bad}$, without significance), would, we feel, have done better to have hedged his comment by manipulating grammatical structure. This would have reduced the baldness of the statement and made it less damaging for the author:

(13b) It can be concluded that / It can be seen that the accuracy of the method is poor. 
Final draft

When one looks at extraposition in the presentations, it is striking that this structure is very rarely used by the native speaker group (only 8 occurrences, a mere $0.4 \%$ of clausal choices, against 51 in their articles). In a previous study (Carter-Thomas \& Rowley-Jolivet, 2001), we accounted for this difference between NS articles and presentations by five main reasons. Firstly, the information given in the extraposed clause of the article is frequently omitted in the presentation, because it is part of either the literature review or the Material and Methods section, which are both much shorter in presentations. Secondly, the need for extraposition to avoid placing a heavy complex theme in sentence-initial position does not apply in the presentations since, as previously mentioned, in half of the clauses the role of theme is filled by a pronoun and in other cases themes are much shorter. A third important reason concerns extraposition as a hedging tactic. NS presenters tend to express their evaluation and comment congruently in the presentation, using personal pronouns and active verbs rather than extraposition. In addition, the combination of a passive with extraposition, used frequently in the articles as a depersonalised hedging strategy, is never encountered in the NS presentations, as the following comparative passages illustrate:

$\begin{array}{ll}\frac{\text { NS Article }}{\text { NS Presentation }} \\ \text { It can be implied that } & \text { We know } \\ \text { It is believed that } & \text { We believe } \\ \text { It is hoped that X } & \text { X was a thought }\end{array}$

A final reason for the quasi-absence of extraposition in NS presentations is that intratextual references to visuals, often made with an extraposed clause in the article (it can be seen in fig. 3 that), use inversion, deictics and active verb forms in the presentations (here's a picture of).

NNS however differentiate much less than NS do between the 2 modes, using extraposition less in the articles, but appreciably more in their presentations (18 occ., $1.5 \%$ of clausal choices). This can perhaps be partly explained by the fact that NNS frequently use periphrastic modals such as it was not possible to, it is not necessary to, no doubt under the influence of their native tongue, where a NS uses a modal auxiliary when speaking (we can't, you may not need to). Secondly, as mentioned above, NNS have a less interactive oral style and make little use of the pronoun you to address the audience directly, preferring to retain the greater interpersonal distance that is characteristic of the research article, as the following pair of examples shows:

$\underline{\text { NNS presentation }}$

(14) to characterize the plasma it is important to know
NS presentation

(15) to get a maximum linearity, you want to apply as 
Final draft

the electronic temperature $(\mathrm{P} 18)$

high a field... (P3)

Along similar lines, NNS seem reluctant to assert their opinions and evaluative comment in the first person singular $I$, using extraposition instead on several occasions. Where a NS says

(16) I guess that I would still regard that as good agreement (P6)

the NNS prefers:

(17) It appears that the actual calculations made by the code are quite in agreement with analytical calculations (P12)

It would seem therefore that NNS show less grammatical flexibility or adaptability to the information packaging requirements of the discourse, resulting both in a less well balanced distribution of information and in poorer rhetorical appropriacy.

\section{Inversion}

Inversion is another syntactic structure that can be used to manipulate the positioning of elements in the clause, thus creating a different information packaging arrangement. The reversal of the canonical or unmarked English SV(O) sequence can be achieved in two ways:

i) Subject / Operator (or partial) inversion, as in 'No sooner did he begin to speak than...'

ii) Subject / Verb (or full) inversion, as in 'From this aisle opens Room III'

Both kinds of syntactic manipulation are triggered by some element other than the subject being placed in clause-initial position. We will not examine Subject/Operator inversion further here, as only 3 occurrences were found in the data.

Inversion of the verb and syntactic subject, in contrast, is frequently used in the oral data, with 64 occurrences in the NS presentations and 21 in the NNS presentations. In all cases, the fronted constituent is a locative adverbial expression and the verb is the copula BE.

On this axis is electric field (P1)

Given $\rightarrow$ New

In example (18), the fronting of the place adverbial on this axis triggers Subject/Verb inversion and enables the nominal group electric field to be presented as New in the rhematic part of the clause. In the canonical 
Final draft

arrangement, as in the manipulated example (18b), the nominal group would normally be considered as already Given or familiar information.

$$
\text { Electric field is on this axis }
$$

\section{Given ?}

The role of this structure in information packaging is thus presentational in nature; the referent introduced becomes cognitively accessible and can then be taken up as theme in a following clause:

\section{$\rightarrow$ New}

here's a picture of one of the devices. This one has plastic insulation, it runs to 2 or $300 \mathrm{kV}$ reliably... (P1)

Subject/Verb inversion is highly mode-dependent in the data (only 1 occurrence in the articles against 85 in the presentations). The high frequency of this structure in scientific presentations appears to be motivated by three features of the communicative context (Carter-Thomas \& Rowley-Jolivet, 2001). Firstly, all the fronted place adverbials have a deictic function, pointing either to a whole new visual that is projected, or to a particular place on that visual (see Table 4). Indeed, it is striking that out of the 64 inversions with here in the 2 oral corpuses, the great majority are the first words that the speaker pronounces as a new visual (V) is placed on the overhead projector:

$$
\begin{aligned}
& \text { V11 here's a picture of the EMBL source it's } \\
& \text { V12 here's the output waveform from the EMBL rising } \\
& \text { V13 here again is received electric field signal, the }
\end{aligned}
$$

Once the audience's attention has been directed to the visual channel by the use of the deictic unit here's, the speaker can then go on to detail the new information to be presented in the rest of the clause. The high frequency of this form of inversion is therefore directly related to the discourse context of the conference presentation, where the speaker has to 'manage' simultaneously, and to integrate, information from two channels of communication, the visual and the verbal. We would follow Enkvist (1991) here, in calling this a text strategy, a strategy which in this case overrules the canonical SVO word order. It is the requirements of the discourse which determine the information packaging arrangements used and the consequent choice of syntactic structures.

A second related point is that these initial place adverbials also function to segment the text into sections or text units. Each visual that is projected can be seen as constituting a text-unit, with inversion signalling the onset of a new unit. In some cases, there are sub-parts or hyponymies within the unit, and these are 
Final draft

also often signalled by the fronting of another place adverbial. Thus, after having signalled the start of a new unit with here's when the visual first appears, the speaker then goes on, when commenting on the same visual, to signal sub-parts with other inversions:

(20) Here's a typical confrontation with the experimental and computer simulation data

On the left are the [experimental] measurements...

and on the right are the corresponding curves (P6)

This allows the speaker to break up the complex visual information on the slide into more digestible segments and to guide the audience through the commentary.

A third feature of the communicative context which motivates speakers' use of inversion concerns endweight in the clause. In all the cases of inversion, the noun group is much weightier than the initial element, and contains the New information:

(21) here is two measurements of power density as a function of angle away from the central line of the horn antenna (P8)

(22) on your upper left is a 3MW alternator we've developed and tested that has a specific power of about 7.8 $\underline{\mathrm{kW}}$ per kg (P4)

Inversion enables the speaker to place the heavy elements towards the end of the clause, thus easing the mental processing effort for the listener and creating an information flow that is adapted to the demands of real-time speech.

NNS presenters, however, use inversion 3 times less frequently, and seem to be less aware of what is in fact a very natural packaging strategy in the context of the audio-visual scientific conference presentation (see Table 4). In all likelihood, this lack of awareness is due to the fact that here / there inversion is never used in the RA.

On several occasions in the NNS presentations there are cases where we feel a subject/verb inversion would have been appropriate or even expected but was not used:

(23) The gas are introduced in vortex in the upper part of the torch and flows down to the ambient air.

The operating conditions are presented here, the power is fixed between five and seven kilowatts and the frequency is equal to five point two megahertz. (P18)

The speaker is describing what can be seen on the slide projected. However, the operating conditions referred to are not yet Given information and the positioning of this element at the beginning of the clause where the 
Final draft

listeners would generally expect to find Given information to occur disrupts the discursive flow. Although grammatically acceptable, a subject/verb inversion would have been more pragmatically appropriate in this context. The adverbial here is contextually Given (the speaker is pointing to the relevant position on the slide) and it would have been clearer for the audience if the speaker had presented the nominal group as New in the rhematic part of the clause, especially as the operating conditions are then detailed in the following clauses.

The task of integrating the two channels of communication makes specific linguistic demands on the scientific presenter, and requires the use of an information packaging structure that appears to be relatively unfamiliar to NNS presenters.

\section{Pseudo-clefts}

As several studies have observed (Banks 1995; Biber et al, 1999; Jucker 1997), pseudo-clefts, either ordinary WH clefts $(\mathrm{WH})$ or reverse WH clefts $(\mathrm{RWH})$, have a very marked mode-dependent distribution. Our data confirm this: there are no occurrences at all in either the NS or NNS articles but a significant number (28) in the NS presentations. In the NNS presentations, however, the pseudo-cleft is practically non-existent (1 occurrence). Before analysing this marked difference between the two groups of speakers, we will first examine the function of pseudo-clefts as an information packaging strategy.

\subsection{WH-clefts}

Ordinary WH-clefts (WH) have the following form: WH-P' is $\mathrm{X}$

What we did was....

WH-clefts do not change the canonical information structure pattern theme/rheme. The initial relative clause is presented as background information and the cleft item is presented as New in the usual rhematic position. However, thanks to the cleft construction the division between Given and New is highlighted, and as a result the listener is encouraged to pay attention to the 'new' elements, which receive additional focus.

(25) So what do I mean by pulse sharpening using non-linear ferroelectric dielectrics?

Well, what we're talking about here is pulses in the voltage range of 10 to $40 \mathrm{kV}$ with a peak current in the range of ... (P3)

Given

New 
Final draft

This example comes right at the beginning of the NS talk. The information in the WH part of the cleft is presupposed as the speaker has just raised the issue, which is in fact the subject of the talk, in the preceding rhetorical question. The cleft thus enables attention to be drawn to the forthcoming information. Without the cleft the information would have received less impact.

(25b) These are pulses in the voltage range of 10 to $40 \mathrm{kV} \ldots$

When we compared the NS use of pseudo-clefts in the oral papers with the passages in the articles that contain the same information, we found very little explicit highlighting or focussing of the kind found in the presentations. Writers just give the bare facts.

The WH-cleft could also be considered as an interactive strategy, implying some sort of questioning process (Thompson, 1996: 126). In the above example (25) the speaker actually asks this question himself but in many WH-clefts there would seem to be an underlying presupposed question that either the audience is likely to ask at that stage, or that the researchers asked themselves at that point.

Q [What did you do then?/ What shall we do now?]

(26) So what we did here was took a lot of data with different gas pressures.....

This might help explain why WH-clefts are only found in oral data - either conversation or our conference presentations - as the dialogic dimension is much more present, even if the speaker is delivering a monologue.

\subsection{RWH-clefts}

In reverse WH-clefts (RWH), the clefted constituent occurs in sentence initial position:

$$
\mathrm{X} \text { is WH-P' }
$$

(27) It's really important how fat the dipole is. That's what this slide shows (P1).

Unlike the regular WH-cleft, where the canonical information packaging arrangements are respected, in RWH-clefts the highlighted focal information occurs in thematic position and the backgrounded relative clause appears rhematically:

(28) This is what it all looks like in the lab (P2)

New (or focus) Given 
Final draft

The fact that demonstratives ${ }^{9}$ are almost invariably used as the cleft constituent seems particularly significant: the speaker is constantly engaged in pointing, or showing, the way so that the participants can orient themselves in the discourse.

(29) and then this is what its all looks like at the thyraton end (P2)

(30) ....it's really important how fat the dipole is, that's what this slide shows (P1)

In each case, the clefted constituent is presented as foregrounded newsworthy information. However, as can be seen from the examples given here (and confirmed by the other examples in the data), this and that fulfil different functions. This has a deictic function in our corpus, pointing forward to the new visual information projected on a slide. That relates more to the verbal channel, summarising for the audience a previous segment of discourse. The anaphoric role of that here does not prevent it from being presented as 'new' or focal, for as we pointed out earlier (see section 2, 'Information Structure') the degree of referential newness of particular items is not necessarily relevant to the distribution of 'Newsworthiness' in the clause complex, which is more of a relational concept.

The judicious use of this and that reverse WH-clefts serves to integrate the two channels of communication, the visual and the verbal. Through the explicit chunking of the information conveyed into two distinct parts, the audience is also given specific processing instructions as to the scope of the sentence focus.

Both RWH-clefts and the ordinary WH-cleft would therefore seem ideally suited to the interactive nature of the audio-visual conference presentation. As with inversions, the text strategy of creating text units, or fairly short portions of texts which are clearly bounded (marked for onset and close) is dictated by the discourse context, and entails the use of certain specialised structures which are very little used in scientific writing.

\subsection{NS / NNS use of pseudo-clefts}

This difference in needs and information strategy is not however reflected in the NNS corpus (only 1 occ., see Table 2). Once again, as with extraposition, it would seem that the NNS in our sample simply prefer to follow the syntactic patterns of writing rather than using information packaging arrangements more appropriate for a live communicative event.

The ordinary WH-cleft structure, in particular, is regularly used by NS presenters to highlight their particular research decisions and their most significant findings as in the following examples from the reference corpus:

\footnotetext{
${ }^{9}$ Biber et al 1999, also refer to these constructions as demonstrative WH-clefts.
} 
What we found was that...

What this work has shown is ...

So what we decided to do was ...

The fact that NNS make very little use of this structure implies therefore that they are not highlighting their particular research contribution sufficiently. As Berkenkotter \& Huckin (1995) and Bazerman (1988) have pointed out, research communications have to say something new and argue for the novelty or originality of their claim. The pseudo-cleft is a very efficient syntactic structure in oral discourse for emphasising the New, and its non- or underuse by NNS therefore weakens the rhetorical persuasiveness of their discourse.

The fact that the RWH is also used considerably less by the NNS probably indicates that they are not sufficiently integrating the verbal and visual channels. Channel-switching can be frequent and rapid in the scientific presentation - the audience requires clear guidance as to where their attention needs to be directed. If the NNS fail to provide the audience with clear instructions, their presentations will be more difficult to follow and process.

\section{Conclusion}

By focusing on one specific, but central, linguistic notion - that of information structure - we have sought to throw light on the articulation between genre, syntactic choices, and rhetorical appropriacy. We have seen how the use of certain syntactic structures in preference to others is pragmatically motivated by the contextual requirements of the discourse. As the processing constraints and the types of co-enunciative relationships in the research article and conference presentation are radically different, different information packaging strategies are required. This in turn means that different specialised structures, or the same structures used in different proportions, are needed in order to package information effectively.

In the proceedings articles, for example, the passive is a frequently used structure, as it enables writers to manage the complex noun groups typical of scientific writing and to maintain thematic continuity between clauses. Extraposition is likewise frequent in the articles as it allows the heavy information load to be distributed in a balanced way over the clause and also provides the writer with a grammatical framework for expressing stance or evaluation while at the same time, like the passive, respecting the impersonal tone expected in this genre. In the oral presentation, in contrast, different information packaging strategies are required, given the differences in information load, cognitive processing, and enunciative context between the oral and written genres. Inversion, which enables the enunciator to integrate the two channels of communication (visual and 
Final draft

verbal) used in scientific conference presentations, and also to chunk the discourse into easily manageable units for the audience, proves to be a particularly effective and relevant information packaging strategy in this genre. Pseudo-clefts fulfil a similar role in the presentation, and in addition enable speakers to highlight the newsworthiness of their research in a suitably interactive way.

NS and NNS scientists differ considerably, however, in their syntactic response to contextual requirements. Whereas NS writers and speakers appear to adapt their information packaging strategies in response to the genre, this is not necessarily the case for NNS. In general it would seem that NNS scientists in our sample differentiate far less between written and spoken modes of scientific communication than their NS peers; in the presentations in particular, the over-reliance on structures more suitable for the RA is striking. Not only extraposition but also passive constructions are consistently overused in NNS presentations. This not only makes their oral discourse much more difficult for the listener to comprehend and process, but also creates a different speaker ethos to that of NS scientists, one characterised by less subtle marking of stance and a much greater interpersonal distance with the audience.

The influence of RA writing norms would also seem to be reflected in the absence of structures such as inversion and pseudo-clefts in NNS presentations, probably because they are never used in the research article which here exerts a negative influence. As pointed out earlier however, both inversion and pseudo-clefts are useful in helping to integrate the visual and verbal channels, playing an important role in breaking down the information into smaller chunks that are easier to process in real time, and in indicating salience and focus. The fact that NNS do not exploit such structures means that their presentations often lack these essential pointers, weakening their clarity and rhetorical impact. All these features, when taken in isolation, may not seem crucial misapplying or underusing the specialised information packaging structures does not constitute a serious 'error' or make the discourse incomprehensible. When such features co-occur, however, they have a negative impact on the rhetorical appropriacy of the discourse, its cognitive processing, and its persuasiveness.

We therefore suggest that more attention should be paid, in second-language teaching of English for academic and/or specific purposes, to acquiring the pragmatic competence needed to manipulate information structure in genre-specific ways. An important first step is one of consciousness-raising and would involve heightening learners' awareness, and perhaps that of ESP instructors too, of the wide range of genres of scientific communication. As both published research on spoken academic genres and the oral data themselves are scarce ${ }^{10}$, conference presentations have perhaps received rather scant attention in ESP didactics. In view of this,

\footnotetext{
${ }^{10}$ The MICASE (Michigan Corpus of Academic Spoken English) should contribute to filling this gap. Unfortunately, however, the MICASE corpus lacks what we regard as the essential dimension of visual communication provided by filmed recordings.
} 
Final draft

it is hardly surprising that NNS presenters tend to rely on the genre they know best - the RA - and to transfer the same information packaging strategies over into their presentations. It seems essential, therefore, to familiarise learners with both the written and oral modes of science as well as with the different semiotics (natural language, visual communication, and formal languages) they call upon. Various kinds of data can be used for this, and if parallel data such as used in this study are difficult to find, instructors can also make use of other types such as student internship presentations, university lectures and extracts from television programmes on science, which can then be compared to the more readily available written science genres. Different exercises based around multi-modal and generic transfer can then be implemented, such as bi-directional transformations of a given message (oral $\leftrightarrow$ written, visual $\leftrightarrow$ spoken, or visual $\leftrightarrow$ written) so as to increase learners' knowledge of the differing communicative and contextual requirements and subsequent language choices within the genres studied.

It would also seem necessary to adopt a more discoursal approach to the teaching of syntax in ESP. Information structuring strategies in order to be effective have to be adapted to the genre, communicative context and audience. Input on the frequency of occurrence of specialised structures in, for example, the presentation and RA and on the various manipulations and permutations observed provide a useful starting-point for discussion on the reasons behind the use of different syntactic patterns in different genres. Second language learners can in this way be familiarised with a range of appropriate structures for oral presentations, and given the confidence to use syntactic patterns they would otherwise avoid or that they may even be unaware of (such as pseudo-clefts). Moreover, by taking into account the multi-semiotic nature of scientific communication and not just the 'text', learners become aware that certain linguistic structures (such as inversion and reverse clefts) are particularly adapted for the integration of different semiotics into a coherent whole. Globally, the links between syntactic structures, speaker ethos and audience interaction are heightened and learners are thus further sensitised to the rhetorical purpose of the discourse. Mastery of the information flow in a second language is thus shown to be more than just a question of using 'correct' English and also one of using an English that is rhetorically appropriate for the genre in question. 


\section{Appendix 1}

The data used in this study comprise oral presentations given at the following physics conferences; the articles are from the Book of Proceedings of the same conferences.

1. Euro Electromagnetics. International symposium on electromagnetic environments and consequences. Bordeaux, May 30 - June 4, 1994.

2. $15^{\text {th }}$ International Symposium on Plasma Chemistry (ISPC 15). Orléans, 9-13 July 2001.

The titles of the 18 proceedings articles $(\mathrm{A})$ and the corresponding 18 oral presentations $(\mathrm{P})$ are as follows :

\section{Native Speakers}

A1 - P1 Sandia National Laboratories' high power electromagnetic impulse sources

A2 - P2 Stacked Blumlein pulse generators: versatile sources of high power repetitive waveforms

A3 - P3 High voltage pulse sharpening using nonlinear ferrolectric ceramic dielectrics

A4 - P4 Lightweight, tactical prime power for mobile pulsed power applications

A5 - P5 The development of high peak power solid state pulse generators

A6 - P6 Milo experiments and computer simulations

A7 - P7 Low-voltage, explosive whisker emission cathode studies

A8 - P8 Efficiency enhancement of high power vacuum backward-wave oscillators driven by short pulse and long pulse electron beams

A9 - P9 Nonlinear space-charge waves in an axially uniform waveguiding structure

\section{Non-Native Speakers:}

A11 - P11 Plasma sources, ion propulsion and plasma contactors: an active interaction with the space

$\begin{array}{ll}\text { Alasma environment } \\ \text { A12-P12 } & \text { Electrostatic discharge plasma propagation and interaction modelling }\end{array}$

A13 - P13 A summary of transionospheric propagation studies

A14 - P14 High power microwave generation from an axially extracted Vircator

A15-P15 Powerful microwave oscillator of microsecond pulse duration driven by relativistic electron beam

A16 - P16 Method of the straight channel electron multiplier gain evaluation

A17 - P17 Long-conduction-time plasma opening switch development for a new high power generator

A18- P18 Optical spectroscopic diagnostic of an Argon-Hydrogen thermal plasma torch used for silicon

A19 - P19 Prediction of particle parameters near the workpiece in plasma spraying using a 3-D modeling

\section{References}

Banks, D. (1993). Writ in water. Aspects of the scientific journal article. E.R.L.A., Université de Bretagne Occidentale.

Banks, D. (1995). There is a cleft in your sentence: less common clause structures in scientific writing. $A S p$ 7/10, 3-11.

Barber, C. L. (1962). Some measurable characteristics of modern scientific prose. In J. Swales [1985] Episodes in ESP. Pergamon Press.

Barthes, R. (1985). L'Ancienne rhétorique. pp. 85-164 in L'Aventure sémiologique. Paris: Editions du Seuil.

Bazerman, C. (1988). Shaping written knowledge. Madison: University of Wisconsin Press.

Bazerman, C. (1994). Systems of genres and the enactment of social intentions. In A. Freedman \& P. Medway. Genre and the new rhetoric (pp. 79-101). London: Taylor \& Francis.

Berkenkotter, C. \& Huckin, T. (1995). Genre knowledge in disciplinary communication. Hillsdale, NJ: Lawrence Erlbaum.

Biber, D., Johansson, S., Leech, G., Conrad, S., \& Finegan, E. (1999). Longman Grammar of Spoken and Written English. Harlow: Pearson Education Ltd.

Carter-Thomas, S. (2000). La cohérence textuelle - pour une nouvelle pédagogie de l'écrit. Paris: L'Harmattan.

Carter-Thomas, S. \& Rowley-Jolivet, E. (2001). Syntactic differences in oral and written scientific discourse: the role of information structure. $A S p$ 31/33, 19-37. 
Carter-Thomas, S. \& Rowley-Jolivet, E. (forthcoming). Structure informationnelle et genre: le cas de la communication de congrès. In S. Carter-Thomas \& M.M.J. Fernandez-Vest. Structure informationnelle et particules énonciatives - essai de typologie. Paris: L'Harmattan.

Chafe, W. (1982). Integration and involvement in speaking, writing and oral literature. In D. Tannen. Spoken and written language: exploring orality and literacy (pp. 35-53). Norwood, NJ: Ablex.

Chafe, W. (1986). Academic speaking. Proceedings of the $12^{\text {th }}$ Annual Meeting of the Berkeley Linguistics Society (pp. 26-40). Berkeley: University of California Press.

Chafe, W. (1987) Cognitive constraints on information flow. In R.S. Tomlin. Coherence and Grounding in Discourse (pp. 21-51). Philadelphia: John Benjamins.

Chafe, W. \& Danielewicz, J. (1987). Properties of spoken and written language. In R. Horowitz \& S.J. Samuels. Comprehending oral and written language (pp. 84-113). San Diego Academic Press

Dubois, B.L. (1980). Genre and structure of biomedical speeches. Forum Linguisticum V, 140-168.

Dubois, B.L. (1981). Nontechnical arguments in biomedical speeches. Perspectives in Biology and Medicine Spring, 399-410.

Dubois, B.L. (1987). A reformulation of thematic progression typology. Text 7(2), 89-116.

Enkvist, N. E. (1991). Discourse strategies and discourse types. In E. Ventola (pp. 3-22).

Firbas, J. (1992). Functional sentence perspective in written and spoken communication. Cambridge: Cambridge University Press.

Fries, P. H. (1994). On Theme, Rheme and discourse goals. In M. Coulthard. Advances in written text analysis (pp. 229-249). London: Routledge.

Gill, A.M. \& Whedbee, K. (1997). Rhetoric. In T. van Dijk. Discourse as structure and process (pp. 157-184). London: Sage.

Halliday, M.A.K. (1989). Spoken and written language. Oxford: Oxford University Press.

Halliday, M.A.K. (1994). An Introduction to functional grammar. London: Edward Arnold.

Hewings, M. \& Hewings, A. (2002) "It is interesting to note that...": a comparative study of anticipatory 'it' in student and published writing. English for Specific Purposes 21, 367-383.

Hoey, M. (2000). Persuasive rhetoric in linguistics: a stylistic study of some features of the language of Noam Chomsky. In S. Hunston \& G. Thompson (pp. 28-37)

Huckin, T.N. \& Pesante, L.H. (1988) Existential There. Written Communication Vol. 5 (3), 368-391.

Huddleston, R.D. (1971). The Sentence in written English. A Syntactic study based on an analysis of scientific texts. Cambridge: Cambridge University Press.

Hyland, K. (2001). Humble servants of the discipline? Self-mention in research articles. English for Specific Purposes 20, 207-226.

Jucker, A.H. (1997). The Relevance of cleft constructions. Multilingua 16(2/3), 187-198.

Lambrecht, K. (1994) Information Structure and Sentence Form. Cambridge: Cambridge University Press.

MICASE. Michigan Corpus of Academic Spoken English. http://www.hti.umich.edu/m/micase

Nwogu, K. \& Bloor, T. (1991). Thematic progression in professional and popular medical texts. In E. Ventola (pp. 369-384).

Rowley-Jolivet, E. (1998). La communication scientifique orale. Etude des caractéristiques linguistiques et discursives d'un genre. Unpublished $\mathrm{PhD}$ Dissertation. Université de Bordeaux 2, France.

Rowley-Jolivet, E. (2001). Activating the passive. A comparative study of the passive in scientific conference presentations and research articles. Les Cahiers de l'APLIUT Vol. XX(4), 38-52.

Rowley-Jolivet, E. (2002). Visual discourse in scientific conference papers. A genre-based study. English for Specific Purposes 21(1), 19-40.

Sengupta, S., Forey, G., \& Hamp-Lyons, L. (1999). Supporting effective English communication within the context of teaching and research in a tertiary institute: a genre model for consciousness raising. English for Specific Purposes 18, S7-S22.

Simpson, R.C. \& Swales, J.M. (2001) Corpus Linguistics in North America. Ann Arbor: University of Michigan Press.

Swales, J. M. (1990). Genre Analysis. Cambridge: Cambridge University Press.

Swales, J. M. (forthcoming). The genres of today's research world: investigation and applications. Cambridge: Cambridge University Press.

Thompson, G. (1996). Introducing Functional Grammar. London: Arnold.

Thompson, S.E. (1997). Presenting research: A study of interaction in academic monologue. Unpublished $\mathrm{PhD}$ dissertation. University of Liverpool.

Vassileva, I. (2002). Speaker-audience interaction: the case of Bulgarians presenting in English. In E. Ventola et al.

Ventola, E. (1991) Functional and systemic linguistics: approaches and uses. New York: Mouton de Gruyter.

Ventola, E., Shalom, C. \& Thompson, S. (2002). The Language of Conferencing. Peter Lang. 
Final draft 
Elizabeth Rowley-Jolivet is Associate Professor (Maître de Conferences) at the Ecole Supérieure des Procédés Electroniques et Optiques (ESPEO) at the University of Orleans, France. Her research interests include genre analysis, oral and written scientific discourse, visual communication in science, and functional linguistics.

Elizabeth.Jolivet@univ-orleans.fr

Shirley Carter-Thomas is Associate Professor (Maître de Conférences) at the Institut National des Télécommunications (INT), Evry, France. Her research interests revolve around functional and text linguistics, scientific discourse analysis, writing pedagogy and the transition between spoken and written English.

Shirley.Thomas@int-evry.fr 
Final draft

$\begin{array}{lllll} & \text { NS Oral } & \text { NNS Oral } & \text { NS Articles } & \text { NNS Articles } \\ \text { \# texts } & 9 & 9 & 9 & 9 \\ \text { \# tokens } & 19,734 & 15,358 & 19,674 & 20,265 \\ \text { \# clauses } & 2,063 & 1,239 & 1,489 & 1,275 \\ \text { Av. Clause length } & 9.5 \text { words } & 12.4 \mathrm{w} . & 13.2 \mathrm{w} . & 15.9 \mathrm{w} .\end{array}$

Table 1. Clause length, NS and NNS articles and presentations 
Final draft

\begin{tabular}{llllllllllc} 
& \multicolumn{2}{c}{ NS Oral } & \multicolumn{2}{c}{ NNS Oral } & \multicolumn{2}{c}{ NS Articles } & \multicolumn{2}{c}{ NNS Articles } & ACAD & CONV \\
Passives & $171(8.3 \%)$ & 212 & $(17.1 \%)$ & 480 & $(32.2 \%)$ & 405 & $(31.7 \%)$ & + & - \\
Extraposition & 8 & $(0.4 \%)$ & 18 & $(1.5 \%)$ & 51 & $(3.6 \%)$ & 31 & $(2.4 \%)$ & + & - \\
Inversion & 64 & $(3 \%)$ & 21 & $(1.6 \%)$ & 1 & & 2 & & - & + \\
pseudo-clefts & 28 & $(1.4 \%)$ & 1 & $(0 \%)$ & 0 & & 0 & & - & + \\
It-clefts & 3 & & 0 & & 2 & & 0 & & + & - \\
Existential There & 52 & $(2.5 \%)$ & 26 & $(2 \%)$ & 13 & $(0.9 \%)$ & 12 & $(1 \%)$ & $\cong$ & $\cong$
\end{tabular}

Table 2. Occurrences of specialised structures

(percentages are in relation to the total number of clauses) 


\begin{tabular}{|c|c|c|c|c|}
\hline \multirow{2}{*}{$\begin{array}{l}\% \text { clauses with pronoun } \\
\text { syntactic subject }\end{array}$} & NS Pres ${ }^{\text {n. }}$ & NNS Pres ${ }^{\text {n. }}$ & NS Articles & NNS Articles \\
\hline & $46.8 \%$ & $40.8 \%$ & $9.9 \%$ & $16.5 \%$ \\
\hline Of which: & $20 \%$ & $13.6 \%$ & $0 \%$ & $0 \%$ \\
\hline You & 23 & 6.7 & 0 & 0 \\
\hline $\mathrm{He}$ & 0 & 0 & 0 & 0 \\
\hline She & 0 & 0 & 0 & 0 \\
\hline It & 17 & 17 & 52 & 31 \\
\hline One & 1.8 & 0.6 & 2 & 4.7 \\
\hline $\mathrm{We}$ & 34 & 59 & 36 & 59 \\
\hline They & 4 & 2.7 & 10 & 5.2 \\
\hline Of which: they animate & 0.7 & 0.8 & 0 & 0 \\
\hline $\begin{array}{l}\% \text { clauses with animate } \\
\text { pronoun subject }\end{array}$ & $37.3 \%$ & $33 \%$ & $3.7 \%$ & $10.5 \%$ \\
\hline
\end{tabular}

Table 3. Distribution of personal pronoun syntactic subjects. 


\section{Fronted element}

here (here's / here are)

there (there's / there are)

Other locative adverbials

(on this axis, out to the left, in the centre... etc.)

TOTAL

$\begin{array}{cc}\text { NS Presentations } & \text { NNS Presentations } \\ 46 & 18 \\ 8 & 3 \\ 10 & 0 \\ 64 & 21\end{array}$

Table 4. Subject/Verb Inversion in NS \& NNS presentations. Clause-initial place adverbials 
Genre awareness and rhetorical appropriacy: manipulation of information structure by NS and NNS scientists in the conference setting.

$$
\text { Elizabeth Rowley-Jolivet }{ }^{\mathrm{a}} \text {, Shirley Carter-Thomas }{ }^{\mathrm{b}}
$$

${ }^{a}$ Ecole Supérieure des Procédés Electroniques et Optiques, Université d'Orléans, 12 rue de Blois, BP 6744, 45067 Orléans, France.

${ }^{b}$ Institut National des Télécommunications, Département Langues et Sciences Humaines, 9 rue Charles Fourier, 91011 Evry, France. 